\author{
Marquette University \\ e-Publications@Marquette
}

Electrical and Computer Engineering Faculty

Research and Publications

Electrical and Computer Engineering,

Department of

\title{
Optimal Design of IPM Motors With Different Cooling Systems and Winding Configurations
}

\author{
Alireza Fatemi \\ Marquette University \\ Dan M. Ionel \\ University of Wisconsin - Milwaukee \\ Nabeel Demerdash \\ Marquette University, nabeel.demerdash@marquette.edu \\ Thomas W. Nehl \\ General Motors
}

Follow this and additional works at: https://epublications.marquette.edu/electric_fac

Part of the Computer Engineering Commons, and the Electrical and Computer Engineering Commons

\section{Recommended Citation}

Fatemi, Alireza; Ionel, Dan M.; Demerdash, Nabeel; and Nehl, Thomas W., "Optimal Design of IPM Motors With Different Cooling Systems and Winding Configurations" (2016). Electrical and Computer Engineering Faculty Research and Publications. 208.

https://epublications.marquette.edu/electric_fac/208 


\title{
Marquette University
}

\section{e-Publications@Marquette}

\section{Faculty Research and Publications/Department}

This paper is NOT THE PUBLISHED VERSION; but the author's final, peer-reviewed manuscript. The published version may be accessed by following the link in th citation below.

IEEE Transactions on Industry Applications, Vol. 52, No. 4 (July/August 2016): 3041-3049. DOI. This article is (C Institute of Electrical and Electronics Engineers (IEEE) and permission has been granted for this version to appear in e-Publications@Marquette. Institute of Electrical and Electronics Engineers (IEEE) does not grant permission for this article to be further copied/distributed or hosted elsewhere without the express permission from Institute of Electrical and Electronics Engineers (IEEE).

\section{Optimal Design of IPM Motors With Different Cooling Systems and Winding Configurations}

\author{
Alireza Fatemi \\ Department of Electrical and Computer Engineering, Marquette University, Milwaukee, WI \\ Dan M. Ionel \\ Department of Electrical and Computer Engineering, University of Kentucky, Lexington, KY \\ Nabeel A. O. Demerdash \\ Department of Electrical and Computer Engineering, Marquette University, Milwaukee, WI \\ Thomas W. Nehl \\ General Motors Global Research and Development, Pontiac, MI
}

Performance improvement of permanent magnet (PM) motors through optimization techniques has been widely investigated in the literature. Oftentimes the practice of design optimization leads to derivation/interpretation of optimal scaling rules of PM motors for a particular loading condition. This paper demonstrates how these derivations vary with respect to the machine ampere loading and ferrous core saturation level. A parallel sensitivity analysis using a second-order response surface methodology followed by a large-scale design optimization based on evolutionary algorithms are pursued in order to establish the variation of the relationships between the main design parameters and the performance characteristics with respect to the ampere loading and magnetic core saturation levels prevalent in the naturally cooled, fan-cooled, and liquid-cooled machines. For this purpose, a finite-element-based platform with a full account of complex geometry, magnetic core nonlinearities, and stator and rotor losses is used. 
Four main performance metrics including active material cost, power losses, torque ripple, and rotor PM demagnetization are investigated for two generic industrial PM motors with distributed and concentrated windings with subsequent conclusions drawn based on the results.

\section{SECTION I}

\section{INTRODUCTION}

The design and modeling of permanent magnet (PM) motors has consistently been a subject of special interest in the literature due to the distinctive features of such machines, including but not limited to high efficiency, and high power density, which makes them suitable for high-performance applications. $\frac{1,2}{\text { Recent }}$ design trends rely on large-scale design optimization techniques based on electromagnetic (EM) finiteelement (FE) analysis of design candidates for high-fidelity calculation of their performance metrics. $\underline{3}$ In some studies, coupled EM/thermal models have been utilized to accurately model the multiphysics nature of the design problem. $., 5,6,7$ In many others, a fixed current density with reference to the machine's cooling system, and accordingly an engineering guess of the operating temperatures of various components are assumed. $\frac{8,9,10,11,12,13}{}$ Although the coupled EM/thermal models offer relatively reasonable predictions of temperature distributions inside such machines, which can be used either to update the material properties for a subsequent iteration of the EM FE analysis until a convergence is reached, $\underline{4}$ or to determine the maximum current density limit based on the winding temperatures, $\underline{\underline{5}}$ the uncoupled approach is faster. The uncoupled optimization approach can also be as effective, provided that the design problem is well defined and that the thermal performances of the optimal designs are examined at the final stages of the design process. The post-design optimization thermal modeling $\underline{14}$ is usually done in order to identify the parameters of the cooling system such as the type of surfaces or the coolant flow rate. $\underline{15}$ Since more efficient designs are achieved through the design optimization, the cooling system is anticipated to remove lesser magnitudes of losses than those associated with motors constructed on the basis of traditional design methods.

The design optimization practice is often accompanied by establishing the optimal scaling rules for achieving a particular improvement in the machine performance. Accordingly, design recommendations for mitigation of torque ripples, minimization of power losses, and reducing dependency on rare-earth PMs, have been often reported in the literature for naturally cooled (NC) machines. $.10,11,16,17$ Nevertheless, increasing the stator winding current density or the machine's ampere loading elevates the flux level and, hence, the saturation level throughout the machine's magnetic circuit. This not only affects the machine performance, but also alters the correlation between them and the geometric design parameters associated with the machine cross-section. In, $\underline{\underline{18}}$ the influence of ampere loading and magnetic saturation on the cogging torque, back electromotive force, and the torque ripple of PM machines was investigated. However, the impacts of the geometric design parameters on these performance metrics was not considered. In, $\underline{19}$ nonlinear scaling rules for low power density brushless PM synchronous machines were developed without taking the effects of ampere loading and magnetic core saturation into account.

This paper contains further contribution through a parallel investigation of the relations between the geometric design parameters and the performance metrics of interior PM (IPM) motors for a wide range of ampere-loading levels determined by the machine's cooling system. $\underline{\underline{20}}$ This is accomplished through a systematic sensitivity analysis and large scale design optimization. Accordingly, it will be demonstrated that 
one set of design rules, such as those derived in, $\underline{\underline{19}}$ cannot be generalized to all three classes of cooling systems.

In order to account for the distinctive performance characteristics of the integral and fractional winding IPM machines, two mainstream case-study industrial IPM machine configurations with distributed and fractional slot concentrated windings (FSCW) are considered. In essence, while FSCW machines offer reduced copper losses owing to shorter end windings, $\underline{21}, \underline{22}$ they suffer from higher core losses as a result of the space harmonics introduced by more "discrete" nature of the stator magnetomotive force (MMF)

waveform. $\underline{23}$ Furthermore, FSCW machines are less susceptible to the torque ripple due to their intrinsically lower cogging torque. This will lead to different correlations of the geometric design parameters with these performance metrics as will be discussed in the paper.

\section{SECTION II}

\section{BENCHMARK DESIGNS}

The parametric cross-sections of the studied machines and their full-fledged 2-D time-stepping FE (TSFE) models are discussed in this section.

\section{A. Parametrized Cross Sections}

Two generic industrial IPM motors with similar rotor configurations, though with different slot-pole combinations are considered.

1. The first case-study is a 48-slot, 8-pole motor with a single-layer distributed winding configuration, see Fig. 1(a). For brevity, this design will be referred to as the 48S8P machine.

2. The second case study is a 12-slot, 10-pole motor with a double-layer concentrated winding configuration, see Fig. 1(b). Hereafter, this design will be denoted as the 12S10P machine. 

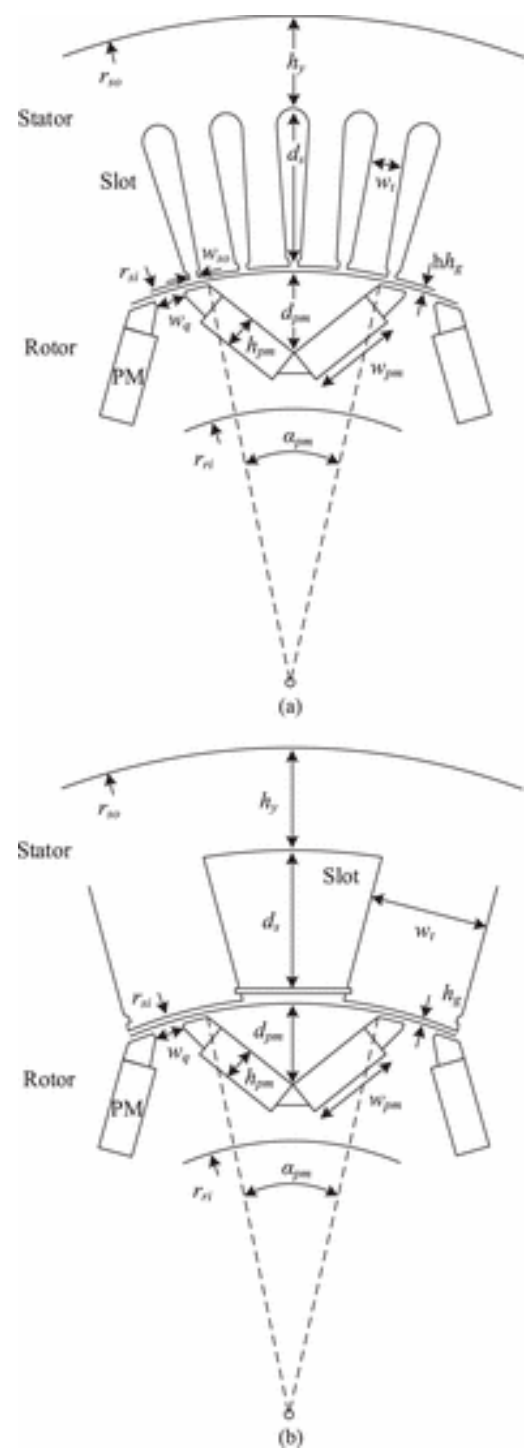

Fig. 1. Cross-sections of the parameterized models of the studied IPM motors consisting of (a) single-layer distributed, and (b) all-toothwound concentrated windings.

The design parameters in Fig. 1 are rationalized according to Table I in order to avoid geometric conflicts between the structures of various components of the two motors. The parameterized FE model of the 48S8P motor is comprised of a total of ten independent design variables, five residing in the rotor, four residing in the stator, in addition to the air-gap height. The 12S10P motor under investigation has one less independent design variable due to its open slot configuration, thus eliminating the parameter associated with the tooth tip. 


\begin{tabular}{|c|c|c|c|c|c|}
\hline \multirow[b]{2}{*}{$\operatorname{Parameter}\left(x_{i}\right)$} & \multirow[b]{2}{*}{ Description } & \multicolumn{2}{|c|}{$48 \mathrm{~S} 8 \mathrm{P}$} & \multicolumn{2}{|c|}{$12 \mathrm{~S} 10 \mathrm{P}$} \\
\hline & & $x_{i, \min }$ & $x_{i, \max }$ & $x_{i, \min }$ & $x_{i, \max }$ \\
\hline$k_{\mathrm{si}}$ & $r_{\mathrm{si}} / r_{\mathrm{so}}$ & 0.60 & 0.70 & 0.60 & 0.70 \\
\hline$h_{g}(\mathrm{~mm})$ & Fig. 1 & 0.70 & 2.50 & 0.70 & 2.50 \\
\hline$k_{w_{t}}$ & $w_{t} / w_{s}^{\mathrm{a}}$ & 0.35 & 0.75 & 0.35 & 0.75 \\
\hline$k_{w_{t t}}$ & $w_{\mathrm{tip}} /\left(w_{\mathrm{so}}+w_{\mathrm{tip}}\right)^{\mathrm{b}}$ & 0.30 & 0.80 & NA & NA \\
\hline$k_{d \mathrm{pm}}$ & $d_{\mathrm{pm}} / d_{\mathrm{pm}, \max }$ & 0.25 & 0.50 & 0.25 & 0.50 \\
\hline$k_{w \mathrm{pm}}$ & $w_{\mathrm{pm}} / w_{\mathrm{pm}, \max }$ & 0.80 & 0.93 & 0.80 & 0.93 \\
\hline$k_{w q}$ & $w_{q} / w_{q, \max }$ & 0.50 & 0.90 & 0.50 & 0.90 \\
\hline$h_{\mathrm{pm}}(\mathrm{mm})$ & Fig. 1 & 3.8 & 9.0 & 3.8 & 9.0 \\
\hline$\alpha_{\mathrm{pm}}$ (deg.) & Fig. 1 & 20 & 32 & 19 & 26 \\
\hline$h_{y}(\mathrm{~mm})$ & Fig. 1 & 13 & 25 & 13 & 25 \\
\hline
\end{tabular}

${ }^{\mathrm{a}} w_{s}$ is the slot-pitch

${ }^{\mathrm{b}} w_{\mathrm{tip}}$ is the tooth-tip width.

Table I Independent Design Variables and Their Bounds

The design variables are confined by upper and lower bounds, also listed in Table I, either to prevent the unintended intersection of various boundary surfaces of components or to address mechanical constraints, e.g., minimum air-gap height or yield stress of the rotor bridges. $\frac{19}{}$ Nevertheless, wide bounds are designated to allow a full exploration of the design space during the optimization procedure. For both machines, the stator outer and the rotor inner (shaft) diameters are fixed to 260 and $111 \mathrm{~mm}$., respectively.

\section{B. TSFE Model}

The 2-D TSFE models of the two machines were developed in ANSYS Maxwell. The core laminations are assumed to be nonoriented silicon steel of $0.36 \mathrm{~mm}$ thickness. The remenance and coercivity of the $\mathrm{NdFeB}$ PMs, and the resistivity of the copper of the stator windings are evaluated corresponding to temperatures of 100 and $150^{\circ} \mathrm{C}$, respectively. This is in order to account for the lowest magnet field and highest winding resistance.

The TSFE analysis with sinusoidal current excitation is utilized to compute the following performance metrics of interest.

1. Active material cost (AMC): The normalized $A M C$ is given below:

$$
\mathrm{AMC}=24 \cdot m_{\mathrm{pm}}+3 \cdot m_{\text {copper }}+m_{\text {steel }}
$$

where the mass, $m$, is in $\mathrm{kg}$ and the steel cost is considered as the one-unit reference in this normalized/per-unit formulation. It can be assumed that the AMC is an approximate indication of the total cost of each motor configuration, given that the manufacturing expenses of the same 
motor topology with identical winding configuration is usually comparable for different design solutions.

2. Power losses: The power losses consist of copper losses in the stator windings with approximations of the end winding copper losses, core losses including hysteresis and eddy current losses in the stator and rotor laminated cores, and the eddy current losses in the rotor PMs for the 12S10P machine with the assumption that these eddy currents are resistance limited. For accurate calculation of the core losses, the frequency domain core loss model introduced in $\underline{24}$ is utilized. The core losses have been obtained on an element by element basis for an excitation current frequency corresponding to a rotor speed of $1800 \mathrm{r} / \mathrm{min}$.

3. Torque ripple: Following the calculation of the average torque per unit length, $T_{\text {ave, }}$ using TSFE analysis, the stack lengths of the designs are adjusted to produce the desired average torque of 300 $\mathrm{N} \cdot \mathrm{m}$ for a stator current density specifically chosen according to the cooling system of the machine. The torque ripple, $T_{r}$, is subsequently determined from the torque profile over a full fundamental ac cycle using (2)

$$
T_{r}=\left(T_{\max }-T_{\min }\right) / T_{\text {ave }} .
$$

4. PM demagnetization: PM demagnetization effects are characterized by the minimum flux density in the rotor PMs over a complete ac cycle. Demagnetization is considered at the magnet piece level. Using NdFeB PMs with reduced heavy earth dysprosium (Dy) content $\frac{25}{}$ can offer local demagnetization protection, assuming that reasonable measures, such as introducing air pockets around vulnerable areas, $\underline{\underline{26}}$ are adopted at the final stages of the design.

The excitation current densities considered for the TSFE analysis accounts for the type of the cooling system. Typical numbers are given in Table II. $\underline{27}$ Here, the fixed current densities of 4,8 , and $16 \mathrm{~A} / \mathrm{mm}^{2}$ are assumed for NC, fan-cooled (FC), and liquid-cooled (LC) machines, respectively.

\begin{tabular}{l|l|l|l}
\hline \hline Cooling & Natural & Fan & Liquid \\
\hline Current density $\left(A / \mathrm{mm}^{2}\right)$ & $1.5-5$ & $5-10$ & $10-30$ \\
\hline \hline
\end{tabular}

Table II Typical Current Density Ranges for Different Cooling Systems

The phase angle of the current vector is chosen so as to ensure maximum torque per ampere (MTPA) operation. Since the design candidates can be saturated, particularly in FC and LC classes, the torque angle at MTPA for each individual design is numerically calculated by sampling and interpolating the generated torque at multiple phase angles of the stator current phasor. $\underline{11}, \underline{28}$

\section{SECTION III}

\section{SENSITIVITY ANALYSIS}

The variation of the relationships between the geometric design parameters and the performance metrics can be understood by carrying out a sensitivity analysis at the three levels of stator winding current density. In the following sections, the sensitivity analysis methodology and the results are presented. 


\section{A. Methodology}

For each cooling system, five second-order response surfaces were defined corresponding to the cost, copper losses, core losses, torque ripple, and degree of PM demagnetization. The core losses and copper losses were treated separately since the design variables have distinctive effects on these two loss components.

The regression coefficients pertaining to these response surfaces indicate how the variation of the design parameters within their permissible ranges influences the machine performance metrics. The class of central composite designs $\underline{29}$ was used for design of experiments (DOE) in order to calculate the regression coefficients associated with each second-order response surfaces, $y$, given in (3),

$$
y=\beta_{o}+\sum_{i=1}^{n} \beta_{i} c_{i}+\sum_{i=1}^{n} \beta_{\mathrm{ii}} c_{i}^{2}+\sum_{i=1}^{n} \sum_{j=i+1}^{n} \beta_{\mathrm{ij}} c_{i} c_{j}
$$

where $B_{0}, b_{i}, b_{i i}$, and $B_{i j}$ are the regression coefficients for the $n$ design variables, $x_{i}$, expressed in the coded form, $c_{\mathrm{i}}$, according to $\underline{(4)}$

$$
c_{i}=\frac{x_{i}-\left(x_{i, \max }+x_{i, \min }\right) / 2}{\left(x_{i, \max }-x_{i, \min }\right) / 2}, i=1,2, \ldots, n .
$$

In Fig. 2, the regression coefficients of the sensitivity analysis are shown for the five examined performance metrics at the three different levels of current densities accounting for the three classes of cooling systems. Since the purpose of the sensitivity analysis is to provide a measure of importance of each design parameter with respect to other design variables, the regression coefficients are normalized to the variable with the maximum influence in each group of metrics. Furthermore, the DOE is conducted so as to ensure no main effect or two-factor interaction is aliased with any other main effect or two-factor interaction of the design variables, i.e., so called resolution $V$ designs. $\underline{29}$ Therefore, the regression coefficients can be examined independently for each group of metrics. 


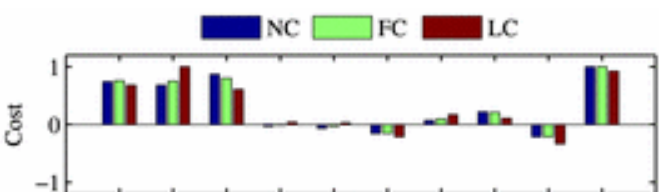

(a.1)

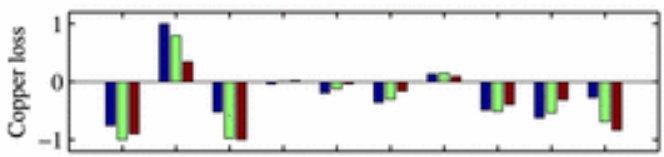

(a.2)

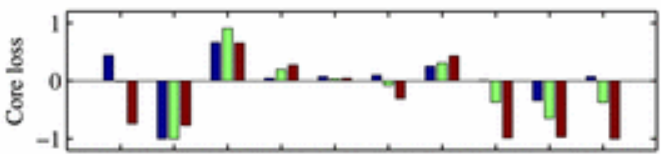

(a.3)

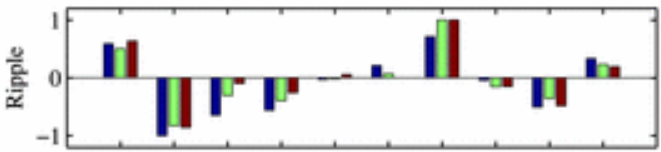

(a.4)

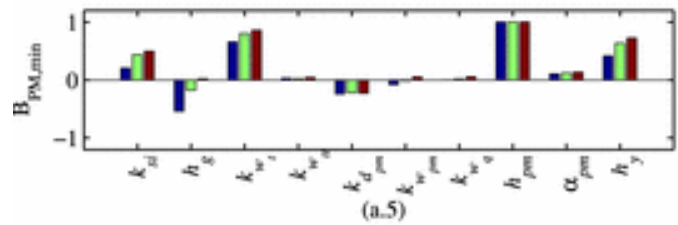

(a)

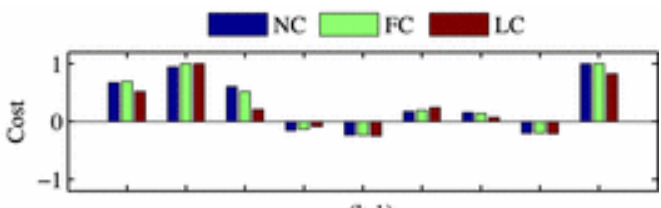

(b.1)
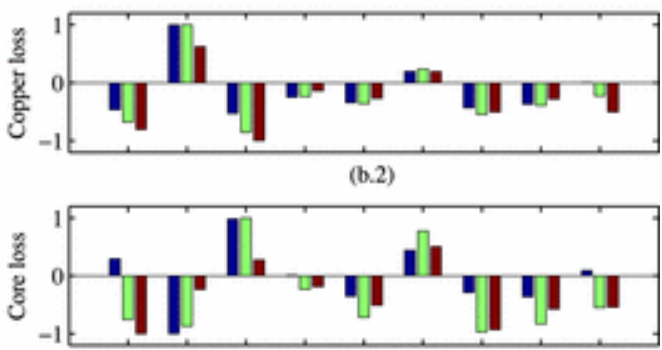

(b.3)
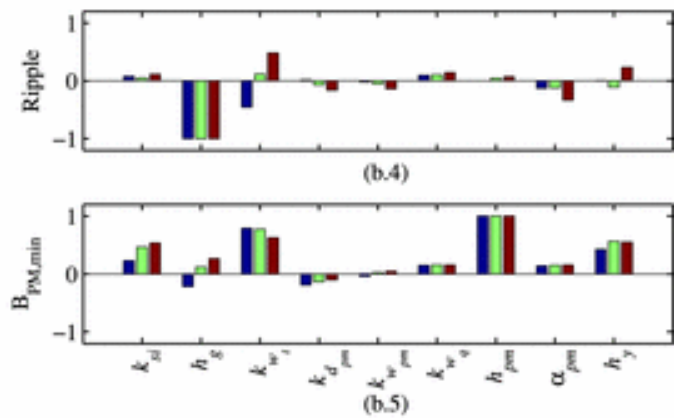

(b)

Fig. 2. Normalized regression coefficients from the sensitivity study indicating the effect of the design variables on, AMC, copper loss, core loss, minimum PM flux density, and torque ripple for (a) the 48S8P machine, and (b) the 12S10P machine.

Each coefficient is associated with a design variable, i.e., input, to indicate how its variation within the permissible range denoted in Table I would influence the machine's performance, i.e., output. A positive coefficient, (+), indicates that an increase in input will raise the output whereas a negative coefficient, (-), constitutes the opposite trend between the input and output. Accordingly, a close examination of Fig. $\underline{2}$ leads to the observation that some trends vary drastically, or even change direction, with respect to the ampere loading for the two 48S8P and 12S10P machines.

B. Discussion of the Results of the Sensitivity Analysis

The sensitivity analysis for each performance metric is summarized in this section.

1) $A M C$

According to Fig. 2(a.1) and (b.1), for both machine configurations.

1. The strongest correlation with $\mathrm{AMC}$ in the $\mathrm{NC}$ and FC classes is attributed to the yoke height, which is opposite to the slot depth for a given stator bore.

2. The yoke height correlation with AMC is superseded by that of the air-gap height in the LC class.

3. The positive correlation of the tooth stem width with AMC monotonically decreases as the ampere loading level increases. 


\section{2) Copper Losses}

According to Fig. 2(a.2) and (b.2).

1. The considerable variations of the influences of the design parameters on the copper losses as the ampere loading level increases should be noted for both machine configurations.

2. For the 48S8P machine, the air-gap height constitutes the strongest correlation with copper losses in the NC class. In the FC and LC classes, the split ratio, $k_{\mathrm{si}}$, the tooth-stem width, and the yoke height become more influential.

3. Similar trends exist for the 12S10P machine, except for the diminished influence of the yoke height.

\section{3) Core Losses}

According to Fig. 2(a.3) and (b.3).

1. The influences of the design parameters on the core losses are sensitive to the ampere loading to such an extent that some of these relationships, i.e., those associated with the stator inner diameter and yoke height, are reversed as the ampere-loading increases.

2. For both machine configurations, in the NC class, the design parameters associated with the stator constitute the strongest correlation with the core losses.

3. As the ampere loading increases, the design parameters associated with the rotor become more influential.

4. The strong influence of the rotor $q$-axis bridge on the core losses, especially in the 12S10P motor, should be noted.

\section{4) Torque Ripple}

According to Fig. 2(a.4) and (b.4).

1. Except for the air-gap height which maintains a strong negative correlation with torque ripple under any ampere loading conditions, the two machine configurations have distinctive torque ripple characteristics.

2. For the 48S8P machine, the width of the $q$-axis bridge becomes more influential than the air-gap height as the level of ampere-loading increases. Meanwhile, the negative correlation of the widths of the tooth stem and tooth tips with torque ripple diminishes as the saturation level of the magnetic core is elevated.

3. As opposed to the 48S8P machine, the $12 \mathrm{~S} 10 \mathrm{P}$ machine is intrinsically less susceptible to torque ripple under any loading conditions.

4. It is interesting to note the reversal of the correlation between the torque ripple and the tooth stem width under heavy magnetic core saturation in the 12S10P motor.

\section{5) PM Demagnetization}

According to Fig. 2(a.5) and (b.5).

1. For both machine configurations and under all loading conditions, the PM demagnetization is strongly correlated to the PM height and tooth-stem width. 
2. The correlation factors of the split ratio, $k_{\mathrm{si}}$, and the yoke height monotonically increase as the level of ampere loading increases.

3. Although the air-gap height constitutes a negative correlation with $B_{\mathrm{pm}}$ in NC machines, this relationship reverses as the ampere-loading level increases.

\section{SECTION IV}

\section{STATISTICAL ANALYSIS OF THE OPTIMIZEDDESIGNS}

The sensitivity analysis merely reveals the independent effects of the design variables on the machine performance. To understand how the interactions between these variables influence the final optimal design which is subject to a unique set of objectives and constraints, a close examination of the design optimization process and results is in order. Nevertheless, the sensitivity study suggests that the optimal designs for each class should have distinctive features which will be examined in this section.

A large-scale design optimization algorithm has been developed and utilized to optimize the two motor configurations for each level of current densities. The design optimization is followed by a statistical analysis on the optimized designs to find the range of change, i.e., the statistical distribution of the design variables in the optimized designs for each class of cooling systems.

\section{A. Large-Scale Design Optimization}

Six runs of a large-scale design optimization, each composed of 6600 candidate designs, were carried out to optimize the machine model at the three aforementioned levels of current densities.

The optimization algorithm relies on the TSFE model developed in Section II. A combined multi-objective optimization with differential evolution, $\underline{30}$ was implemented as the optimization search algorithm.

The fitness function of the optimization problem has been defined based on the previously discussed performance metrics. For a generic industrial use, it practically consists of the two following objectives: 1 ) minimization of the AMC given in (1); and 2) minimization of the power losses.

Due to the opposite correlations of the design parameters, except the air-gap height, $h_{\mathrm{g}}$, with AMC and power losses in Fig. 2, the two objectives are conflicting.

Furthermore, the two following constraints are introduced for reliable operation: 1 ) less than $15 \%$ torque ripple; and 2) less than 70\% PM demagnetization.

Each run of the optimization was started with an initial generation of 200 members and was carried out over 800 generations of eight members each. $\frac{30}{\mathrm{Fig} .} 3(\mathrm{a})-(\mathrm{b})$ shows the optimization results in terms of the conflicting objectives for the 48S8P and 12S10P machines, respectively. The design candidates indicated in Fig. 3 are compared in terms of AMC and power losses at the same rated load operating point. It is evident that increasing the stator winding current density and, thus, the ampere loading of the machine, complicates the design of the cooling system by increasing the total dissipated losses. Nevertheless, in many applications, higher torque density can translate into reduced system cost, size, and weight, thus promoting such designs with sophisticated cooling systems. $\underline{14}, \underline{26}$ Furthermore, the extremes of the power 
losses and $\mathrm{AMC}$ of the three classes of cooling systems are nonoverlapping. That is, the same efficiency characteristics of NC machines cannot be obtained by LC machines. Similarly, the AMC in LC machines can be reduced to values not achievable by NC machines.

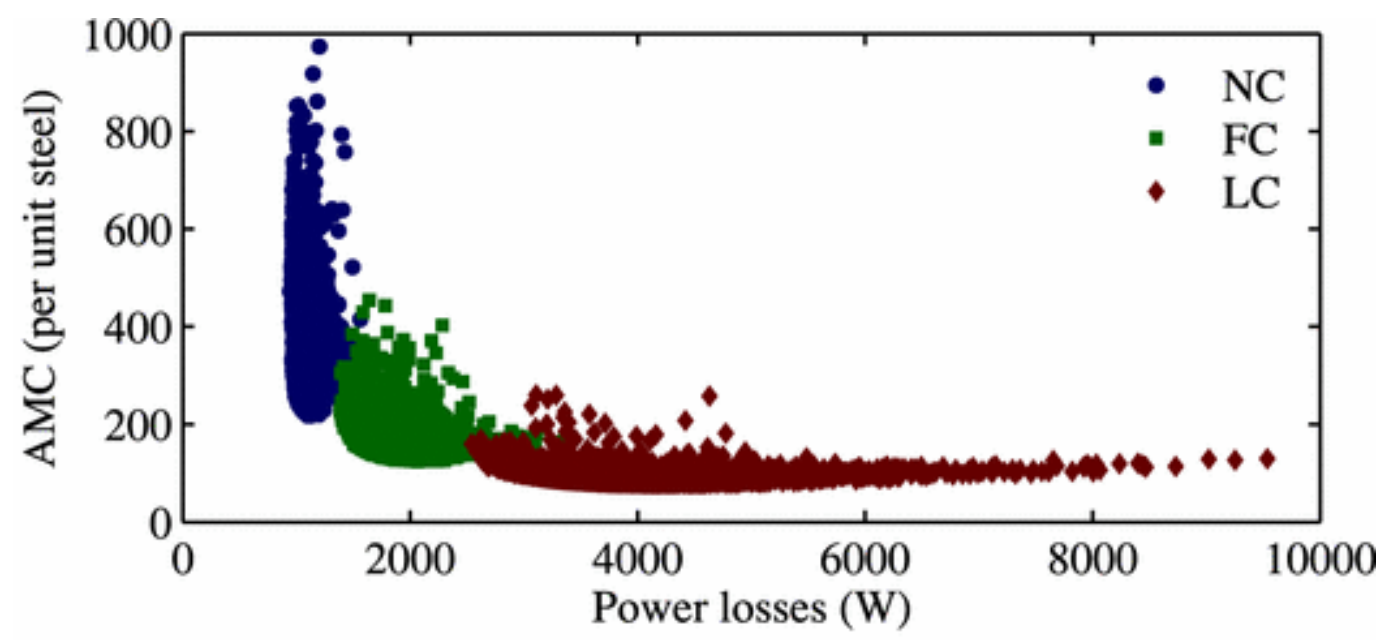

(a)

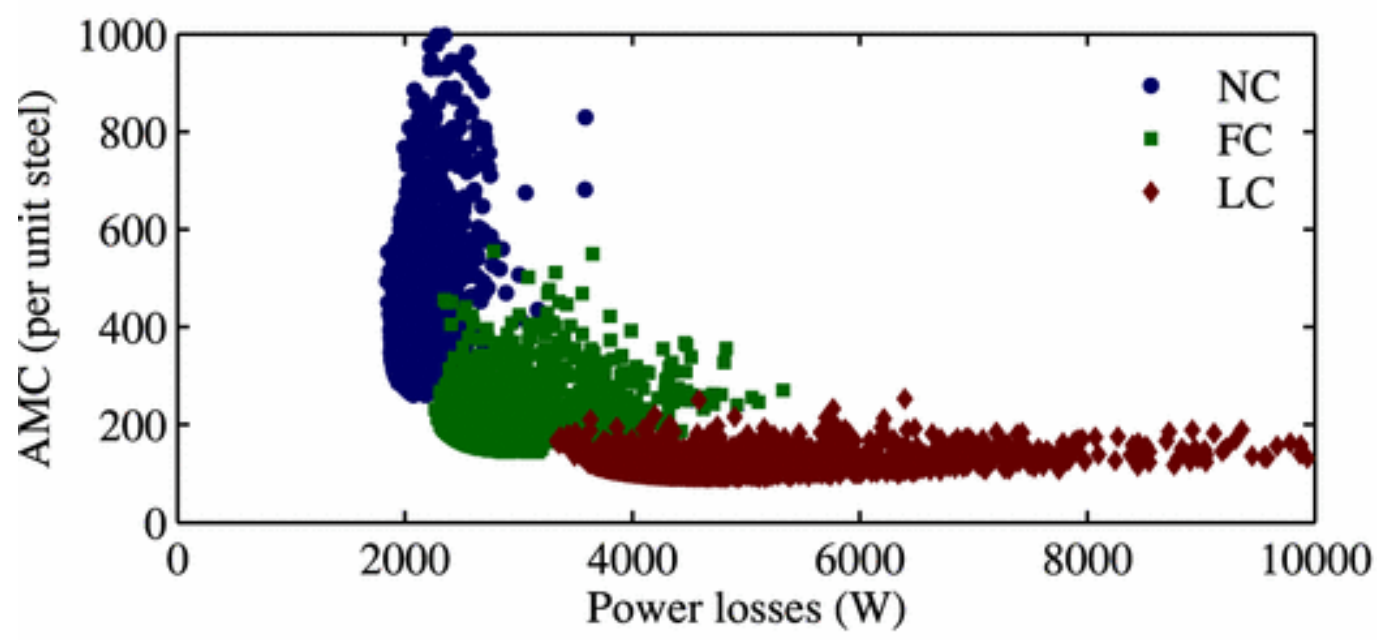

(b)

Fig. 3. Optimization results for the three case-study cooling systems (a) 48S8P, and (b) 12S10P machines. The normalized AMC is defined according to $\underline{(1)}$.

It is interesting to notice that due to higher core losses and larger masses of PM in their construction, the Pareto-optimal designs of the 12S10P configuration are located further apart from the origin as compared to the 48 S8P configuration, see Tables IV and $\underline{\mathrm{V}}$.

\section{B. Scaling Rules of the Optimum Candidate Designs}

To differentiate the distinctive optimal design values between the three cooling classes, the statistical distributions of the design variables in the Pareto-optimal designs should be investigated. For this purpose, from each run of optimization, 500 superior designs were selected based on a three-step process. First, the designs which do not violate the constraints on the torque ripple and on the PM demagnetization are 
identified and separated in set $P$. Subsequently, a strength value $s\left(d_{i}\right)$ is designated to each of the designs, $d^{i}$ in $P$, according to $\underline{(5)}$

$$
\begin{aligned}
s\left(d_{i}\right)= & \#\left\{d_{j} \mid d_{j} \in P \text { and } \operatorname{cost}\left(d_{i}\right)<\operatorname{cost}\left(d_{j}\right) \text { and } \operatorname{loss}\left(d_{i}\right)\right. \\
& \left.<\operatorname{loss}\left(d_{j}\right)\right\}, i=1,2, \ldots, k
\end{aligned}
$$

where "\#" is the cardinality of the set, $\underline{\underline{31}}$ and $k$ is the number of the designs in $P$. The designs in $P$ are thereafter ranked in a descending order based on their strength value, $s_{\mathrm{di}}$, to determine the top 500 superior designs.

The distribution of the design parameters in the selected designs with respect to their bounds can be described by "box plots" shown in Fig. 4. The rectangular boxes in Fig. 4represent the first, the second, and the third quartiles of the distribution of design values with respect to the upper and lower bounds designated for each design parameter in Table I. The distances between the different parts of these boxes indicate the degree of dispersion and skewness in the value of the optimal designs. The circles in the middle, and the whiskers represent the average, the maximum, and the minimum of the optimal design value for each parameter.

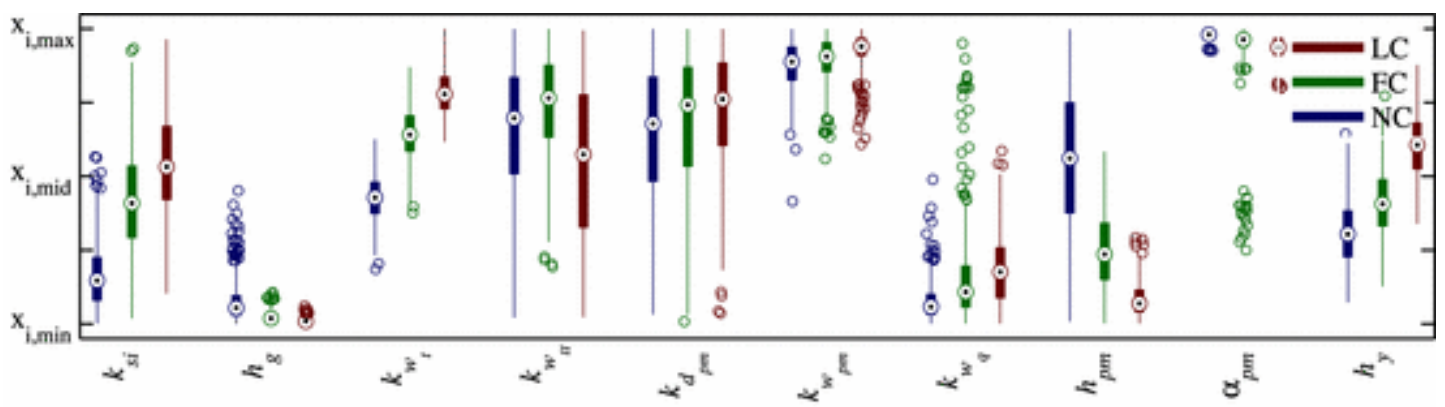

(a)

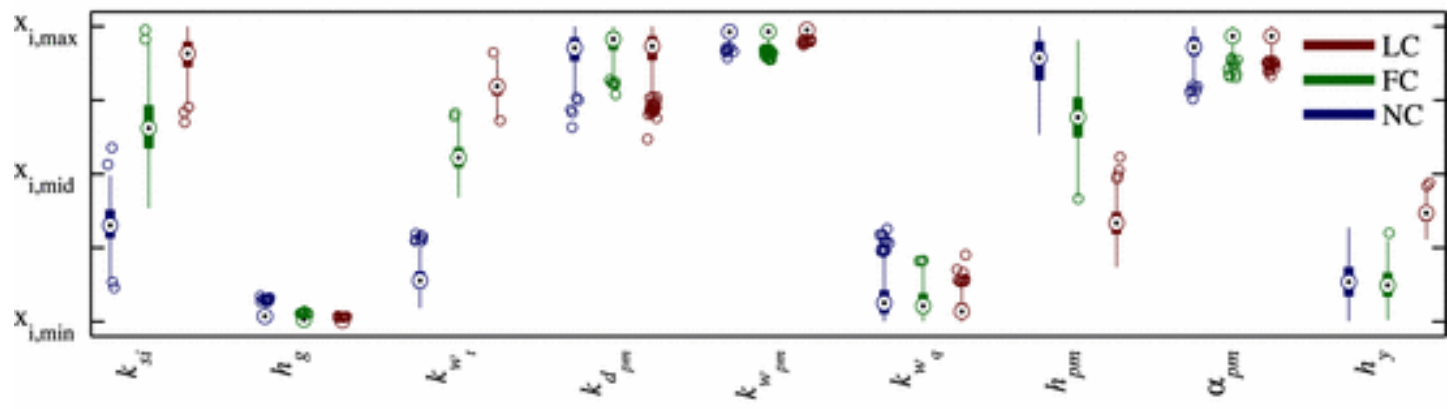

(b)

Fig. 4. Distribution of the design variables in the optimized designs for (a) 48S8P, and (b) 12S10P machines. See Table III for the average values of the optimal design parameters.

The representative cross-sections which were generated based on the means of the design variables in Table III are provided in Fig. 5 which allows one to visualize the distinctive design features of each 
machine. These features will be subsequently explained with reference to the statistical and sensitivity analyses.
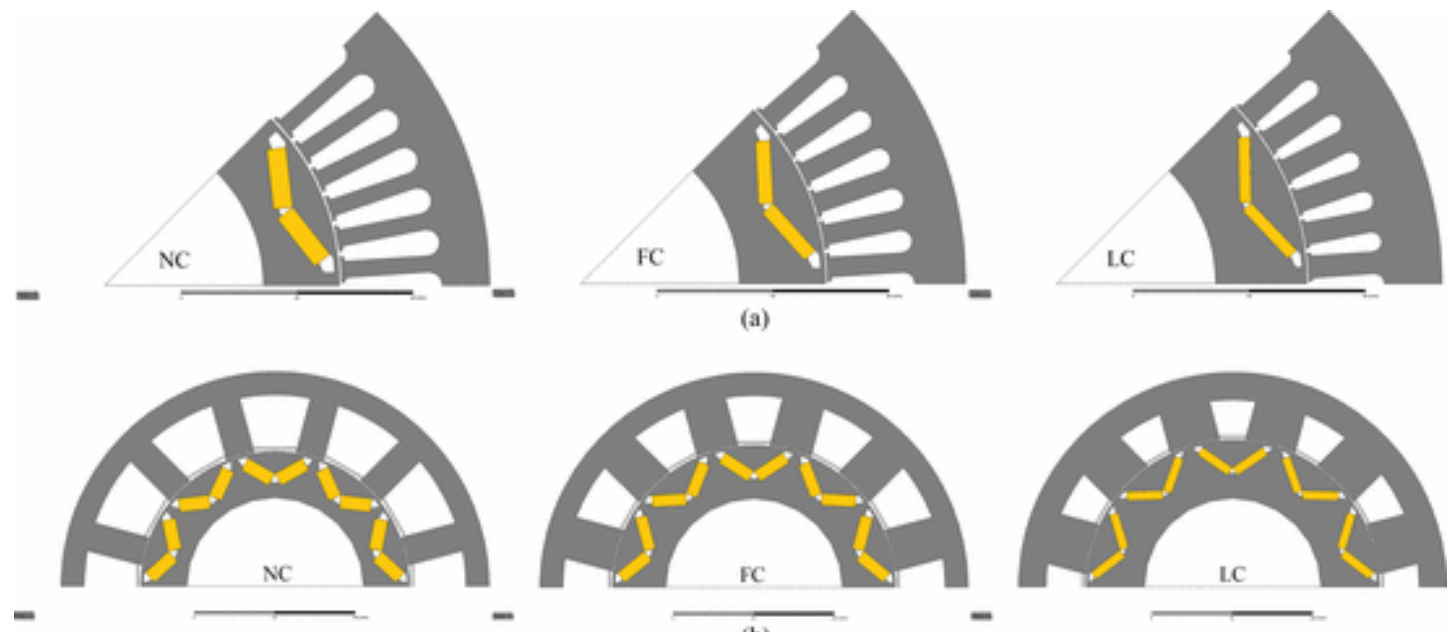

(a)
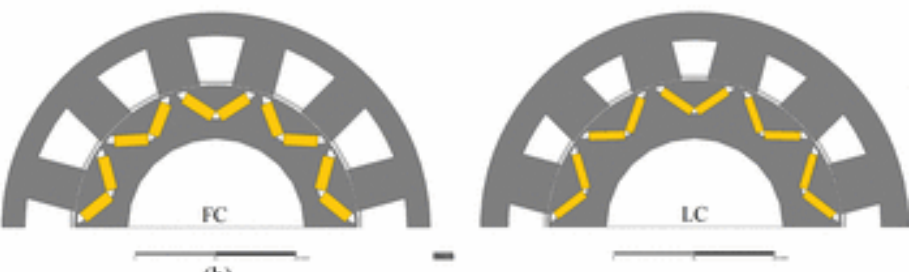

(b)

Fig. 5. Optimized cross sections derived based on the mean of the design variables in the 500 Pareto-optimal designs, see Table III, for the three current density levels: (a) 48S8P, and (b) 12S10P machines.

\begin{tabular}{l|l|l|l|l|l|l}
\hline \hline \multirow{2}{*}{ Parameter $\left(x_{i}\right)$} & \multicolumn{5}{|c|}{$48 \mathrm{~S} 8 \mathrm{P}$} & $\mathrm{FC} 10 \mathrm{P}$ \\
\cline { 2 - 7 } & $\mathrm{NC}$ & $\mathrm{FC}$ & $\mathrm{LC}$ & $\mathrm{NC}$ & $\mathrm{FC}$ & LC \\
\hline$k_{s i}$ & 0.62 & 0.64 & 0.66 & 0.63 & 0.67 & 0.69 \\
$h_{g}(\mathrm{~mm})$ & 0.83 & 0.75 & 0.72 & 0.74 & 0.71 & 0.71 \\
$k_{w_{t}}$ & 0.52 & 0.61 & 0.66 & 0.41 & 0.57 & 0.67 \\
$k_{w_{t t}}$ & 0.63 & 0.67 & 0.57 & $\mathrm{NA}$ & $\mathrm{NA}$ & NA \\
$k_{d_{p m}}$ & 0.41 & 0.42 & 0.43 & 0.48 & 0.49 & 0.48 \\
$k_{w_{p m}}$ & 0.91 & 0.92 & 0.92 & 0.47 & 0.46 & 0.46 \\
$k_{w_{q}}$ & 0.53 & 0.56 & 0.57 & 0.53 & 0.53 & 0.52 \\
$h_{p m}(\mathrm{~mm})$ & 6.71 & 5.06 & 4.22 & 8.38 & 7.40 & 5.55 \\
$\alpha_{p m}(\mathrm{deg})$. & 31.73 & 31.21 & 31.21 & 25.50 & 25.74 & 25.73 \\
$h_{y}(\mathrm{~mm})$ & 16.52 & 17.72 & 20.12 & 14.63 & 14.51 & 17.40 \\
\hline \hline
\end{tabular}

Table III Average Design Parameters in the Selected Optimal Designs

According to Fig. 4, the optimal ranges of the design variables are broader in the 48S8P machine. This stems from the imposed criterion on the torque ripple of the selected designs, which leads to the dispersion of the chosen design candidates in the Pareto-front vicinity.

Three different trends can be recognized in the variation of the design parameters which are addressed in the following discussion. 


\section{1) Parameters With Increasing Trends in Both Motor Configurations}

As can be seen in Fig. 4 , the split ratio, $k_{\mathrm{si}}$, the ratio $k_{w t}$, and the yoke height, $h_{\mathrm{g}}$, relatively grow with the increase of the ampere loading. This is in line with the sensitivity analysis and the fact that decreasing copper losses, as the major loss component in the case study PM machines according to Table IV, takes precedence over decreasing core losses. The $k_{d_{p m}}$ ratio varies widely in the 48S8P machine due to the insignificant correlation of this design variable with the optimization objectives according to the sensitivity analysis in Fig. 2(a). The stronger negative correlation of $k_{d_{p m}}$ ratio with AMC and copper and core losses in 12S10P machine, has resulted in its maximization in the selected 12S10P designs, as shown in Fig. 4(b). Similarly, the $k_{w_{p m}}$ ratio and $\alpha_{\mathrm{pm}}$ are concentrated toward their higher bounds due to their negative correlations with the two objectives as shown in Fig. 2.

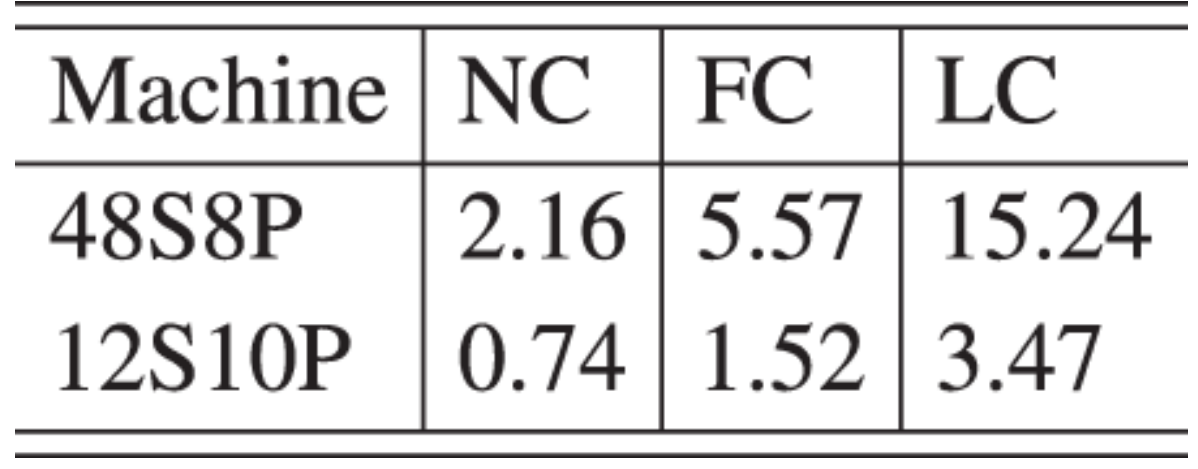

Table IV Mean of the Ratio of Copper Losses to Core Losses in the Pareto-optimal Designs

\section{2) Parameters With Decreasing Trends in Both Motor Configurations}

The PM height, $h_{\mathrm{pm}}$, in Fig. 4 monotonically decreases as the ampere loading increases in both 48S8P and 12S10P machines. This can be explained by considering the results of the sensitivity analysis in Fig. 2 , and the change of the masses of various components in the selected designs for the three cooling systems, as listed in Table V. Accordingly, the PM mass has been reduced in the selected designs proportionately to the masses of other components by reducing the only parameter associated with the PM mass which constitute a positive correlation with AMC, i.e., $h_{\mathrm{pm}}$. Meanwhile, the excessive PM demagnetization as a result of reducing PM height has been prevented by introducing a constraint on the minimum flux density of the PMs. The air-gap height, $h_{g}$, in the optimum designs is minimized due to its positive correlation with AMC and major component of the losses, i.e., copper losses.

\begin{tabular}{l|l|l|l|l|l|l}
\hline \hline \multirow{2}{*}{ Mass $(m)$} & \multicolumn{3}{|c}{ 48S8P } & \multicolumn{3}{c}{ 12S10P } \\
\cline { 2 - 7 } & NC & FC & LC & NC & FC & LC \\
\hline$m_{P M} \%$ & 100 & 47.47 & 26.22 & 100 & 56.53 & 32.60 \\
$m_{\text {copper } \%}$ & 100 & 52.14 & 30.22 & 100 & 45.10 & 23.31 \\
$m_{\text {steel } \%}$ & 100 & 59.88 & 38.34 & 100 & 58.14 & 42.32 \\
\hline \hline
\end{tabular}

Table V Mean of the Masses of the Optimized Designs Normalized With Respect to the Values Obtained for NC Class 


\section{3) Parameters With Conflicting Trends in the Two Motor Configurations}

For the 48S8P machine, while the $k_{w_{q}}$ ratio monotonically increases in Fig. 4(a) as the torque ripple becomes less of an issue, it decreases constantly in the 12S10P machine, Fig. 4(b), in order to reduce the core losses. On the one hand, according to the sensitivity analysis, the core loss has a stronger correlation with this design variable, and on the other hand, the core loss constitute a considerable portion of the overall losses in the 12S10P machine, see Table IV.

The tooth-tip width of the 48S8P machine widely varies at higher ampere loading due to saturation. The tooth tips are larger at low ampere loading to alleviate the torque ripple, see Fig. 2(a.4). Their variation is ineffective when the machine saturates. Meanwhile, the mean of the tooth-tip width in Fig. 4(a) is reduced to mitigate the core losses, although this reduction in width is not significant since the overall ratio of core to copper losses is insignificant, see Table IV.

\section{SECTION V}

\section{CONCLUSION}

A parallel sensitivity analysis was carried out on two case-study IPM machines with concentrated and distributed stator configurations and with different cooling systems. It was demonstrated that the correlation between the main design variables and various performance metrics, particularly core losses, copper losses, and torque ripple can be significantly affected by the machine's ampere loading and magnetic core saturation. In some cases, these trends can even be reversed.

The distribution of the optimal design values were investigated for each case study in a practical optimization problem where the interaction of the performance metrics and design variables occur. Noticeable difference in the optimal design values were observed and the trends were classified for the NC, FC, and LC machines.

\section{Acknowledgment}

The authors would like to thank ANSYS Inc. and Motor Design Limited for the software support.

\section{FOOTNOTES}

Paper 2015-EMC-0898.R1, presented at the 2015 IEEE International Electric Machines and Drives Conference, Coeur d'Alene, ID, USA, May 10-13, and approved for publication in the IEEE TRANSACTIONS ON INDUSTRY APPLICATIONS by the Energy Systems Committee of the IEEE Industry Applications Society. This work was supported by General Motors Global Research and Development, and by the Midwest Energy Research Consortium.

\section{REFERENCES}

${ }^{1}$ D. Dorrell, M. Hsieh, M. Popescu, L. Evans, D. Staton and V. Grout. "A review of the design issues and techniques for radial-flux brushless surface and internal rare-earth permanent-magnet motors" IEEE Trans. Ind. Electron., vol. 58, no. 9, pp. 3741-3757, 2011

${ }^{2}$ E. Armando, P. Guglielmi, G. Pellegrino, M. Pastorelli and A. Vagati. "Accurate modeling and performance analysis of IPM-PMASR motors" IEEE Trans. Ind. Appl., vol. 45, no. 1, pp. 123-130, 2009 
${ }^{3}$ Y. Duan and D. lonel. "A review of recent developments in electrical machine design optimization methods with a permanent-magnet synchronous motor benchmark study" IEEE Trans. Ind. Appl., vol. 49, no. 3, pp. 1268-1275, 2013

${ }^{4}$ Y. Wang, D. lonel and D. Staton. "Ultrafast steady-state multi-physics model for pm and synchronous reluctance machines" IEEE Trans. Ind. Appl., vol. 51, no. 5, pp. 3639-3646, 2015

${ }^{5} \mathrm{~W}$. Jiang and T. Jahns. "Coupled electromagnetic/thermal machine design optimization based on finite element analysis with application of artificial neural network" Proc. IEEE Energy Convers. Congr. Expo., pp. 51605167,2014

${ }^{6} \mathrm{~S}$. Semidey, Y. Duan, J. Mayor, R. Harley and T. Habetler. "Optimal electromagnetic-thermo-mechanical integrated design candidate search and selection for surface-mount permanent-magnet machines considering load profiles" IEEE Trans. Ind. Appl., vol. 47, no. 6, pp. 2460-2468, 2011

7J. Wang and D. Howe. "Design optimization of radially magnetized, iron-cored, tubular permanent-magnet machines and drive systems" IEEE Trans. Magn., vol. 40, no. 5, pp. 3262-3277, 2004

${ }^{8} \mathrm{G}$. Sizov, D. lonel and N. Demerdash. "Multi-objective optimization of pm ac machines using computationally efficient - FEA and differential evolution" Proc. IEEE Int. Elect. Mach. Drives Conf., pp. 1528-1533, 2011

${ }^{9}$ G. Lei, C. Liu, J. Zhu and Y. Guo. "Techniques for multilevel design optimization of permanent magnet motors" IEEE Trans. Energy Convers., vol. 30, no. 4, pp. 1574-1584, 2015

${ }^{10} \mathrm{C}$. Xia, L. Guo, Z. Zhang, T. Shi and H. Wang. "Optimal designing of permanent magnet cavity to reduce iron loss of interior permanent magnet machine" IEEE Trans. Magn., vol. 51, no. 12, pp. 1-9, 2015

${ }^{11} \mathrm{~N}$. Bianchi and A. Canova. "FEM analysis and optimisation design of an IPM synchronous motor" Proc. Int. Conf. Power Electron., Mach. Drives, pp. 49-54, 2002

${ }^{12}$ F. Parasiliti, M. Villani, S. Lucidi and F. Rinaldi. "A new optimization approach for the design of IPM synchronous motor with wide constant-power region" Proc. XIX Int. Conf. Elect. Mach., pp. 1-7, 2010

${ }^{13} \mathrm{~F}$. Dubas, C. Espanet and A. Miraoui. "Design of a high-speed permanent magnet motor for the drive of a fuel cell air-compressor" IEEE Conf. Veh. Power Prop., p. 8, 2005

${ }^{14}$ M. Popescu, I. Foley, D. A. Staton and J. E. Goss. "Multi-physics analysis of a high torque density motor for electric racing cars" Proc. IEEE Energy Convers. Congr. Expo., pp. 6537-6544, 2015

${ }^{15} \mathrm{~A}$. Boglietti, A. Cavagnino, D. Staton, M. Shanel, M. Mueller and C. Mejuto. "Evolution and modern approaches for thermal analysis of electrical machines" IEEE Trans. Ind. Electron., vol. 56, no. 3, pp. 871-882, 2009

${ }^{16}$ P. Zhang, G. Sizov, M. Li, D. Ionel, N. Demerdash, S. Stretz and A. Yeadon. "Multi-objective tradeoffs in the design optimization of a brushless permanent-magnet machine with fractional-slot concentrated windings" IEEE Trans. Ind. Appl., vol. 50, no. 5, pp. 3285-3294, 2014

${ }^{17}$ P. Zhang, G. Sizov, D. lonel and N. Demerdash. "Establishing the relative merits of interior and spoke-type permanent-magnet machines with ferrite or ndfeb through systematic design optimization" IEEE Trans. Ind. Appl., vol. 51, no. 4, pp. 2940-2948, 2015

${ }^{18} \mathrm{Z}$. Azar, Z. Zhu and G. Ombach. "Influence of electric loading and magnetic saturation on cogging torque, backEMF and torque ripple of pm machines" IEEE Trans. Magn., vol. 48, no. 10, pp. 2650-2658, 2012

${ }^{19} \mathrm{Y}$. Duan and D. Ionel. "Nonlinear scaling rules for brushless pm synchronous machines based on optimal design studies for a wide range of power ratings" IEEE Trans. Ind. Appl., vol. 50, no. 2, pp. 1044-1052, 2014

${ }^{20}$ A. Fatemi, D. M. lonel and N. A. O. Demerdash. "Identification of design rules for interior pm motors with different cooling systems" IEEE Int. Elect. Mach. Drives Conf. (IEMDC), Coeur d'Alene, ID, pp. 12281234,2015

${ }^{21} \mathrm{~J}$. Cros and P. Viarouge. "Synthesis of high performance pm motors with concentrated windings" IEEE Trans. Energy Convers., vol. 17, no. 2, pp. 248-253, 2002

${ }^{22} \mathrm{~A}$. EL-Refaie. "Fractional-slot concentrated-windings synchronous permanent magnet machines: Opportunities and challenges" IEEE Trans. Ind. Electron., vol. 57, no. 1, pp. 107-121, 2010 
${ }^{23} \mathrm{M}$. Nakano and H. Kometani. "A study on eddy-current losses in rotors of surface permanent magnet synchronous machines" Proc. IEEE 39th IAS Annu. Meeting Conf. Record Ind. Appl. Conf., vol. 3, pp. 16961702,2004

${ }^{24}$ D. Ionel, M. Popescu, M. McGilp, T. Miller, S. Dellinger and R. Heideman. "Computation of core losses in electrical machines using improved models for laminated steel" IEEE Trans. Ind. Appl., vol. 43, no. 6, pp. 1554-1564, 2007

${ }^{25} \mathrm{~K}$. Hirota, H. Nakamura, T. Minowa and M. Honshima. "Coercivity enhancement by the grain boundary diffusion process to nd amp;8211;fe amp;8211;b sintered magnets" IEEE Trans. Magn., vol. 42, no. 10, pp. 2909-2911, 2006

${ }^{26}$ S. Jurkovic, K. Rahman, N. Patel and P. Savagian. "Next generation voltec electric machines; design and optimization for performance and rare-earth mitigation" SAE Int. J. Alt. Powertrains, vol. 4, no. 2, pp. 336-342, 2015

${ }^{27}$ T. J. Miller and J. R. Hendershot. Design of Brushless Permanent-Magnet Machines. 2010, Motor Design Books LLC

${ }^{28} \mathrm{G}$. Pellegrino and F. Cupertino. "FEA-based multi-objective optimization of IPM motor design including rotor Iosses" Proc. IEEE Energy Convers. Congr. Expo., pp. 3659-3666, 2010

${ }^{29}$ R. H. Myers and D. C. Montgomery. Response Surface Methodology: Process and Product Optimization Using Designed Experiments. 2009, Wiley

${ }^{30}$ A. Fatemi, D. M. Ionel, N. A. O. Demerdash and T. W. Nehl. "Fast multi-objective cmode-type optimization of pm machines using multicore desktop computers" IEEE Trans. Ind. Appl., 2016

${ }^{31} Y$. Wang and Z. Cai. "Combining multiobjective optimization with differential evolution to solve constrained optimization problems" IEEE Trans. Evol. Comput., vol. 16, no. 1, pp. 117-134, 2012 